Research Article

\title{
Analysis of the effects of drugs and techniques used in anesthesia on tumour recurrence, metastasis and survival in ovarian serous adenocarcinoma
}

\author{
Sudha P*, Rachel Cherian Koshy
}

Department of Anaesthesiology, Regional Cancer Centre, Trivandrum, Kerala, India

Received: 26 November 2015

Accepted: 07 December 2015

\section{*Correspondence:}

Dr. Sudha P,

E-mail: drsudhap@yahoo.co.in

Copyright: (C) the author(s), publisher and licensee Medip Academy. This is an open-access article distributed under the terms of the Creative Commons Attribution Non-Commercial License, which permits unrestricted non-commercial use, distribution, and reproduction in any medium, provided the original work is properly cited.

\begin{abstract}
Background: Numerous factors affect the risk of recurrence and metastasis after cancer surgery. Studies have observed that anaesthetic techniques have effects on tumour recurrence.

Methods: Medical records of newly diagnosed ovarian serous adenocarcinoma patients who underwent radical hysterectomy with bilateral salpingoopherectomy from 1995-2008 were analysed for the effect of anaesthetic techniques and drugs on tumour recurrence \& metastasis free survival rate and mortality rate. Univariate association between overall survival and anaesthesia technique was assessed using Kaplan-Meier survival estimates and Cox regression. Multivariate association was tested after adjusting potential confounding factors.

Results: The overall survival rate ( $\mathrm{RR}$ at $95 \% \mathrm{CI}=3.16(1.79-5.60)$ was significantly better in patients who received regional anaesthesia for surgery than those who had general anaesthesia. Other factors significantly associated with overall survival rate in univariable analysis were,perioperative blood transfusion,preoperative Ca 125 level, FIGO stage, tumour size and lymphatic metastasis.Kaplan Meier survival curve showed that regional anesthesia group had higher overall survival rate.Recurrence rate did not show significant difference in univariable(Odds $95 \% \mathrm{CI} 1.42 \mathrm{P}=$ 0.273 )and multivariable(Odds $95 \% \mathrm{CI}=0 \mathrm{P}=0.846$ ) analysis.Al1 the 18 patients who had metastasis underwent surgery under GA.

Conclusions: This study showed marked increase in overall survival rate in patients who underwent surgery under regional anaesthesia when compared to those who had surgery under general anaesthesia. Prospective randomized control trials are needed for better evaluation.
\end{abstract}

Keywords: Anaesthetic technique, Survival rate, Ovarian serous adenocarcinoma

\section{INTRODUCTION}

Surgical removal of the primary tumour is the best treatment option for solid tumours. Studies have shown that cancer related deaths occur mostly due to metastasis. ${ }^{1}$ Perioperative period is very critical as a number of factors during this period promote development of metastasis. $^{2}$ Compromised immune defense and tumour seeding leads to increased susceptibility to tumour metastasis during perioperative period. ${ }^{3,4}$ In this context there is increasing interest on the effect of anesthesia and anesthesia techniques in tumour progression suggesting an increased role for the anesthetist in improving long term outcome after cancer surgery. 
There is no strong evidence on the effect of anesthetic technique and drugs on cancer cells although many retrospective studies have shown the beneficial effect of regional anesthesia in reducing cancer recurrence and metastasis after surgery. Chemical mediators released due to surgical stress and general anesthesia results in neuroendocrine, immunological and inflammatory responses. Suppression of immune system through the released chemical mediators may result in tumour progression from preexisting micro metastasis as well as those disseminated during surgical manipulation of tumour. Surgical trauma may contribute to increased lymph flow resulting in accelerated spread of cancer cells during surgery. ${ }^{5} \mathrm{Up}$ regulation of major promalignant pathways by these mediators results in disruption of normal tumour homeostasis promoting local and distant metastasis. Regional anesthesia prevents inhibition of immune system by attenuating surgical stress response. Reduction in systemic opioid requirement for analgesia and decreased regional lymphatic flow during surgery could explain reduction in tumour progression in cancer surgeries done under neuraxialanaesthesia. ${ }^{2}$

\section{Scope and significance of the study:}

Ovarian serous adenocarcinoma is the most common ovarian epithelial tumour. Surgery is the primary and the most effective treatment of excisable ovarian tumours, but minimal residual disease is probably unavoidable. Numerous factors affect the risk of recurrence and metastasis from residual disease. Some studies have observed that different anesthetic techniques have effects on tumour recurrence. ${ }^{6}$ There is considerable decrease in cytokines for cell mediated immunity such as Interleukin (IL) 2, IL 12 and Interferon (IFN)r during major surgeries. The number of circulating NK cells, cytotoxic $\mathrm{T}$ lymphocytes and ratio of $\mathrm{T}$ helper 1 (Th 1) to $\mathrm{T}$ helper 2 (Th 2) cells are also reduced significantly. Attenuation of immunosuppression by regional anesthesia can reduce the risk of tumour progression and metastasis. Epidural supplemented GA decreases both surgical stress response and the adverse effects of surgery on cell mediated immunity. There is also less overall use of opioids and GA drugs.

The anesthetic technique and drugs used depends on presence of absolute or relative contraindications to the technique and drugs, and preference of the anesthetist, surgeon or patient. In Regional Cancer Centre, Trivandrum any of the following techniques are used for laprotomies:

1. General anesthesia (GA)

2. Central neuraxialanaesthesia

3. Epidural supplemented GA

\section{METHODS}

After approval by Institutional review board of Regional Cancer Centre, Trivandrum, Kerala, India this retrospective descriptive study was conducted with the hypothesis that central neuraxial blockade would decrease the risk of tumour recurrence and produce better long term outcome in terms of metastasis free survival and mortality in ovarian serous adenocarcinoma patients undergoing primary surgery.

Medical records of all newly diagnosed ovarian serous adenocarcinoma patients who underwent radical hysterectomy with bilateral salpingoopherectomy from 1995-2008 were analyzed for the following:

1. Anaesthetic techniques and drugs used

The anaesthetic technique and drugs depend on the preference of the anaesthetist, patient or surgeon as well as the presence of absolute or relative contraindications or risks. Those who received general anaesthesia were grouped as $G$ while those who received regional anaesthesia (sub arachnoid block or epidural anaesthesia and analgesia) were grouped as R. Exclusion criteria included loss of follow up and lost or inadequate documentation of medical records.

2. To recognize the outcomes under the study, the outcomes measured were the following:

a) Disease free survival rate without recurrence and metastasis

b) Mortality rate-It gives an idea about overall survival.

Primary endpoint of the study was recurrence and metastasis free survival rate .Secondary end point was overall survival rate.

The comparison of potential confounders was done using $\mathrm{X}^{2}$ test for categorical variables and Mann-Whitney $\mathrm{U}$ test for continuous variables. Univariate association between overall survival and anesthesia technique was assessed using Kaplan-Meier survival estimates and that between overall survival and potential baseline confounders was done using Cox regression. Multivariate association between overall survival and anesthetic technique to obtain relative risk was done after adjusting potential confounding factors independently related with the outcome.

The significance level was 0.05. Those who received epidural supplemented GA were included under regional anesthesia group for analysis of survival rate, recurrence rate and metastasis rate as their number was comparatively very low (9). SPSS software version 11 was used for all the analyses.

\section{RESULTS}

The medical records of 204 patients with newly diagnosed ovarian serous adenocarcinoma who underwent radical hysterectomy with bilateral salpingoopherectomy were reviewed. 21 patients were excluded due to inadequate documentation. 93 patients underwent surgery under general anesthesia and 81 under regional anaesthesia. 9 patients underwent surgery under 
combined general and regional anesthesia. So a total of 183 patients were included in the study. The evaluation cut off time was 31 December 2013.Median follow up time was 138 months with a range of 60 months ( $5 \mathrm{yrs}$ ) to 216 months (18 yrs). Those who received epidural supplemented GA were included under regional anesthesia group for some analyses and were excluded in some analyses for getting exclusive results due to GA or regional anesthesia.

Table 1 shows comparison of groups on the basis of patient characterestics. Charecterestics of the study groups were analyzed based on age of the patient, requirement of perioperative blood transfusion, duration of surgery, status of preoperative CA 125 antigen, tumour size, FIGO stage, histological grade, status of lymphatic metastasis, residual macroscopic tumour and use of perioperative chemotherapy. All these are predictors of disease free survival and overall survival. So these are potential confounders affecting outcome. Group R had more patients with better histological grade ( $\mathrm{p}$ 0.00), smaller tumour size ( $\mathrm{p} 0.00)$, more residual tumour ( $\mathrm{p}$ 0.022 ) and with increased incidence of perioperative chemotherapy ( $p$ 0.003).All the patients above 60 years received GA. All these were statistically significant. Pre op CA 125 level was raised in $82.7 \%$ of group $\mathrm{R}$ and $43 \%$ in group $G$. Presence of pelvic and extra pelvic lymphatic metastasis did not show significant difference in the two groups. Group R had slightly shorter duration of surgeries (p 0.189), better FIGO stage (p 0.609) \& less intraoperative blood transfusion $(\mathrm{P}=0.532)$. (Table 1)

Table 2 shows Cox's regression results of univariable association with survival rate. In this no adjustment is made for potential confounders. Group $G$ had a significantly higher estimated risk of death in comparison with group $\mathrm{R}$ ( $\mathrm{RR}$ at 95\% $\mathrm{CI}=3.16(1.79-5.61)$ (P $0.000)$.There was no significant difference in survival in epidural supplemented GA group. Other factors significantly associated with reduced overall survival rate in univariable analysis were use of perioperative blood transfusion, raised preoperative $\mathrm{Ca} 125$ level, higher FIGO stage, larger tumour size and presence of lymphatic metastasis.

Kaplan Meier survival curve showed that group $\mathrm{R}$ had higher overall survival rate. (Figure 1)

Survival rate at targeted landmark follow up time of 1,3 \& 5 years showed that group $\mathrm{R}$ had higher overall survival rate. 1 year survival rate for $\mathrm{R}$ is $100 \%$ while that of $\mathrm{G}$ is $92.5 \%$.Survival rate at 3 yrs for $\mathrm{R}$ and $\mathrm{G}$ were $93.8 \%$ \& $82.8 \%$ respectively. At 5 yrs it was $87.7 \%$ \& $69.9 \%$.After 5 yrs survival rate of $\mathrm{G}$ decreased more than that of R. (Table 3, Figure 2)

After adjusting the potential confounding factors like perioperative blood transfusion, duration of surgery, preoperative CA125 level, FIGO stage, tumour size and lymphatic metastasis multivariate association with

survival rate using Cox regression model showed that group $\mathrm{G}$ had an increased mortality rate compared to group R (95\% CI RR 6.282 (3.023-13.053) P $\quad$ 0.000) (Table 4)

Univariable association with recurrence did not show significant difference between the two groups (Odds $95 \%$ CI $1.42(0.76-2.65) \mathrm{P}=0.273)$. Other factors significantly associated with recurrence were increased duration of surgery $(\mathrm{P}=0.000)$, raised preop CA 125 level $(\mathrm{P}=0.000)$, higher FIGO stage, higher histological grade, larger tumour size and presence of lymphatic metastasis. (Table 5) Multivariate association with recurrence taking into account the potential confounding factors did not show significant difference between group $\mathrm{R}$ and $\mathrm{G}(\mathrm{P}=0.846)$ (Table 6).Distant metastasis was found in 18 patients. All those patients underwent surgery under general anaesthesia.33.3\% group $\mathrm{R}$ had recurrence. In group $\mathrm{G}$ $48.6 \%$ had recurrence and $32.7 \%$ had metastasis. There was no metastasis in group $\mathrm{R}$. Thus recurrence free status was $66.7 \%$ in group $\mathrm{R}$ and $51.4 \%$ in group $\mathrm{G}$.The metastasis free status was $100 \%$ in group $\mathrm{R}$ and $67.3 \%$ in group G.

The common drugs used for GA were thiopentone sodium (TPS), propofol, vecuronium and pancuronium. Maximum recurrence and metastasis rates were seen with TPS and pancuronium $(71.2 \% \& 48.6 \%)$ and least with propofol and vecuronium (0\%).25 patients did not receive perioperative chemotherapy and all of them had recurrence or metastasis (100\%). 10 patients had no residual tumour and they did not have recurrence or metastasis. In 81 patients with residual tumour 71 had recurrence $(46.7 \%)$ and 18 had metastasis (18.2\%). $68.4 \%$ of patients with pelvic and extra pelvic metastasis had recurrence and $30.5 \%$ without lymphatic metastasis had recurrence. None of the patients without lymphatic metastasis had metastasis where as $50 \%$ with pelvic or extra pelvic metastasis had metastasis.

\section{Survival Functions}

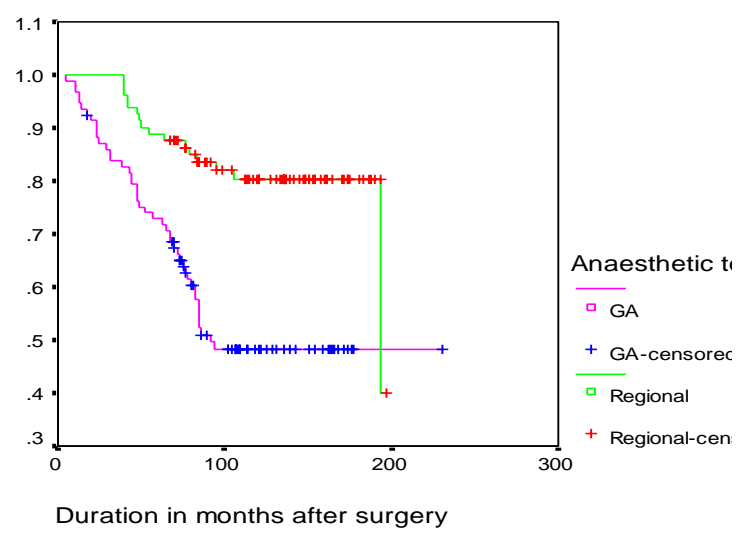

Figure 1: Keplan curve 
Table 1: Patient characteristics and operative characteristics for patients receiving regional anesthesia or GA.

\begin{tabular}{|c|c|c|c|c|}
\hline & & Regional & GA & \multirow{4}{*}{$0.002 \#$} \\
\hline \multirow{3}{*}{ Age } & $<40$ & $10(12.3)$ & $39(41.9)$ & \\
\hline & $40-60$ & $71(87.7)$ & $46(49.5)$ & \\
\hline & $>60$ & $0(0)$ & $8(8.6)$ & \\
\hline \multirow{2}{*}{ Blood transfusion } & No Transfusion & $73(90.1)$ & $81(87.1)$ & \multirow[t]{2}{*}{$0.532 *$} \\
\hline & Transfusion & $8(9.9)$ & $12(12.9)$ & \\
\hline \multirow{2}{*}{ Duration of surgery } & $<3$ hours & $48(59.3)$ & $64(68.8)$ & \multirow[t]{2}{*}{$0.189 *$} \\
\hline & $>3$ hours & $33(40.7)$ & $29(31.2)$ & \\
\hline \multirow{2}{*}{ Pre OP ca 125} & Not Raised & $14(17.3)$ & $53(57)$ & \multirow[t]{2}{*}{$0.000 *$} \\
\hline & Raised & $67(82.7)$ & $40(43)$ & \\
\hline \multirow{7}{*}{ Periop chemo } & No & $7(8.6)$ & $18(19.4)$ & \multirow{7}{*}{$0.003^{*}$} \\
\hline & Carboplatin & $0(0)$ & $3(3.2)$ & \\
\hline & Carboplatin, Paclitaxel & $32(39.5)$ & $26(28)$ & \\
\hline & Carboplatin, Endoxan & $10(12.3)$ & $5(5.4)$ & \\
\hline & Paclitaxel & $23(28.4)$ & $16(17.2)$ & \\
\hline & Carboplatin, Paclitaxel, 5FU & $0(0)$ & $5(5.4)$ & \\
\hline & Taxol, Carboplatin & $9(11.1)$ & $20(21.5)$ & \\
\hline \multirow{7}{*}{ FIGO stage } & $1 \mathrm{a}$ & $29(35.8)$ & $32(34.4)$ & \multirow{7}{*}{$0.609 \#$} \\
\hline & $1 \mathrm{~b}$ & $12(14.8)$ & $8(8.6)$ & \\
\hline & $1 \mathrm{c}$ & $9(11.1)$ & $15(16.1)$ & \\
\hline & $2 c$ & $1(1.2)$ & $0(0)$ & \\
\hline & $3 a$ & $12(14.8)$ & $12(12.9)$ & \\
\hline & $3 b$ & $9(11.1)$ & $8(8.6)$ & \\
\hline & $3 c$ & $9(11.1)$ & $18(19.4)$ & \\
\hline \multirow{2}{*}{ Histological grade } & Grade 1 & $13(16)$ & $53(57)$ & \multirow[t]{2}{*}{$0.000 \#$} \\
\hline & Grade 3 & $68(84)$ & $40(43)$ & \\
\hline \multirow{3}{*}{ Tumour size } & Small & $13(16)$ & $50(53.8)$ & \multirow{3}{*}{$0.000 \#$} \\
\hline & Medium & $68(84)$ & $40(43)$ & \\
\hline & Large & $0(0)$ & $3(3.2)$ & \\
\hline \multirow{2}{*}{ Residual tumour } & No & $10(12.3)$ & $3(3.2)$ & \multirow[t]{2}{*}{$0.022 *$} \\
\hline & Yes & $71(87.7)$ & $90(96.8)$ & \\
\hline \multirow{3}{*}{ Lymphatic mets } & No & $11(13.6)$ & $9(9.7)$ & \multirow{3}{*}{$0.689 *$} \\
\hline & Pelvic & $25(30.9)$ & $28(30.1)$ & \\
\hline & Pelvic, Extra Pelvic & $45(55.6)$ & $56(60.2)$ & \\
\hline
\end{tabular}

Table 2: Univariable association with survival rate: Cox's regression results.

\begin{tabular}{|c|c|c|c|c|}
\hline & & $\mathbf{N}$ & RR $(95 \%$ CI $)$ & P value \\
\hline \multirow{3}{*}{ Anesthetic technique } & Regional & 81 & 1 & 0.000 \\
\hline & GA & 93 & $3.16(1.79-5.61)$ & 0.975 \\
\hline & Combined & 9 & $0(0-0)$ & \\
\hline \multirow{3}{*}{ Age } & $<40$ & 58 & 1 & 0.861 \\
\hline & $40-60$ & 117 & $1707(0-0)$ & 0.874 \\
\hline & $>60$ & 8 & $7108(0-0)$ & \\
\hline \multirow{2}{*}{ Blood transfusion } & No Transfusion & 163 & 1 & 0.000 \\
\hline & Transfusion & 20 & $3.31(1.75-6.29)$ & \\
\hline \multirow{2}{*}{ Duration of surgery } & $<3$ hours & 112 & $1.36(0.80-2.31)$ & 0.255 \\
\hline & $>3$ hours & 71 & 1 & \\
\hline Pre OP ca 125 & Not Raised & 75 & 1 & 0.028 \\
\hline
\end{tabular}




\begin{tabular}{|c|c|c|c|c|}
\hline & Raised & 108 & $1.90(1.07-3.36)$ & \\
\hline \multirow{7}{*}{ Periop chemo } & No & 25 & $1.17(0.63-2.16)$ & 0.623 \\
\hline & Carboplatin & 3 & $0(0-0)$ & 0.987 \\
\hline & Carboplatin, Paclitaxel & 58 & $0.21(0.10-0.44)$ & 0.000 \\
\hline & Carboplatin, Endoxan & 15 & $0(0-0)$ & 0.973 \\
\hline & Paclitaxel & 39 & $0.02(0.00-0.17)$ & 0.000 \\
\hline & Carboplatin, Paclitaxel & 14 & $0.45(0.17-1.20)$ & 0.110 \\
\hline & Taxol, Carboplatin & 29 & 1 & \\
\hline \multirow{8}{*}{ FIGO stage } & 1a & 61 & 1 & \\
\hline & $1 b$ & 20 & $2.86(0.99-8.29)$ & 0.051 \\
\hline & $1 \mathrm{c}$ & 24 & $3.88(1.50-10.07)$ & 0.005 \\
\hline & $2 \mathrm{a}$ & 9 & $0(0-0)$ & 0.977 \\
\hline & $2 c$ & 1 & $0(0-0)$ & 0.992 \\
\hline & $3 a$ & 24 & $5.84(2.40-14.17)$ & 0.000 \\
\hline & $3 b$ & 17 & $3.19(1.15-8.84)$ & 0.025 \\
\hline & $3 c$ & 27 & $6.01(2.60-13.92)$ & 0.000 \\
\hline \multirow{3}{*}{ Histological grade } & Grade 1 & 66 & 1 & \\
\hline & Grade 2 & 9 & $0(0-0)$ & 0.973 \\
\hline & Grade 3 & 108 & $1.64(0.92-2.91)$ & 0.089 \\
\hline \multirow{3}{*}{ Tumour size } & Small & 72 & $0.42(0.23-0.79)$ & 0.000 \\
\hline & Medium & 108 & 1 & 0.007 \\
\hline & Large & 3 & $30.55(8.01-116.51)$ & \\
\hline \multirow{2}{*}{ Residual tumour } & No & 13 & $1.29(0.41-4.13)$ & 0.663 \\
\hline & Yes & 170 & 1 & \\
\hline \multirow{2}{*}{ Lymphatic mets } & No & 121 & 1 & \\
\hline & Pelvic, Extra Pelvic & 62 & $1.82(1.10-3.01)$ & 0.021 \\
\hline
\end{tabular}

Table 3: Comparison of survival rate at different time interval.

\begin{tabular}{|llllllllll|}
\hline & & \multicolumn{9}{c}{ Regional } & & & & GA \\
$\begin{array}{l}\text { Period (in } \\
\text { year) }\end{array}$ & Survival & $\begin{array}{l}\text { No of } \\
\text { events }\end{array}$ & No. Left & $\begin{array}{l}\text { Survival } \\
\text { rate }\end{array}$ & Survival & $\begin{array}{l}\text { No of } \\
\text { events }\end{array}$ & $\begin{array}{l}\text { No. } \\
\text { Left }\end{array}$ & $\begin{array}{l}\text { Survival } \\
\text { rate }\end{array}$ \\
\hline Baseline & 81 & 0 & Baseline & 81 & 0 & Baseline & 81 & 0 \\
\hline 1 & 81 & 0 & 1 & 81 & 0 & 1 & 81 & 0 \\
\hline 2 & 81 & 0 & 2 & 81 & 0 & 2 & 81 & 0 \\
\hline 3 & 81 & 5 & 3 & 81 & 5 & 3 & 81 & 5 \\
\hline 4 & 76 & 3 & 4 & 76 & 3 & 4 & 76 & 3 \\
\hline 5 & 73 & 2 & 5 & 73 & 2 & 5 & 73 & 2 \\
\hline 6 & 71 & 1 & 6 & 71 & 1 & 6 & 71 & 1 \\
\hline 7 & 70 & 2 & 7 & 70 & 2 & 7 & 70 & 2 \\
\hline 8 & 68 & 1 & 8 & 68 & 1 & 8 & 68 & 1 \\
\hline 9 & 67 & 1 & 9 & 67 & 1 & 9 & 67 & 1 \\
\hline 10 & 66 & 0 & 10 & 66 & 0 & 10 & 66 & 0 \\
\hline 11 & 66 & 0 & 11 & 66 & 0 & 11 & 66 & 0 \\
\hline 12 & 66 & 0 & 12 & 66 & 0 & 12 & 66 & 0 \\
\hline 13 & 66 & 0 & 13 & 66 & 0 & 13 & 66 & 0 \\
\hline 14 & 66 & 0 & 14 & 66 & 0 & 14 & 66 & 0 \\
\hline 15 & 66 & 0 & 15 & 66 & 0 & 15 & 66 & 0 \\
\hline 16 & 66 & 1 & 16 & 66 & 1 & 16 & 66 & 1 \\
\hline 17 & 65 & 0 & 17 & 65 & 0 & 17 & 65 & 0 \\
\hline
\end{tabular}


Table 4: Multivariable association with survival rate: Cox's regression model. CI, confidence.

\begin{tabular}{|c|c|c|c|}
\hline & & RR (95\% CI) & P value \\
\hline \multirow{2}{*}{ Anesthetic technique } & Regional & 1 & \multirow{2}{*}{0.000} \\
\hline & GA & $6.282(3.023-13.053)$ & \\
\hline \multirow{2}{*}{ Blood transfusion } & No Transfusion & 1 & \multirow{2}{*}{0.000} \\
\hline & Transfusion & $151.731(38.846-592.653)$ & \\
\hline \multirow{2}{*}{ Duration of surgery } & $<3$ hours & 1 & \multirow{2}{*}{0.002} \\
\hline & $>3$ hours & $2.95(1.507-5.775)$ & \\
\hline \multirow{2}{*}{ Pre OP ca 125} & Not Raised & 1 & \multirow{2}{*}{0.744} \\
\hline & Raised & $2.2(0.019-249.143)$ & \\
\hline \multirow{7}{*}{ FIGO stage } & 1a & 1 & \\
\hline & $1 \mathrm{~b}$ & $1.325(0.465-3.77)$ & 0.598 \\
\hline & $1 \mathrm{c}$ & $1.57(0.592-4.163)$ & 0.365 \\
\hline & $2 \mathrm{a} \& \mathrm{~b}$ & $2.566(0.024-277.651)$ & 0.693 \\
\hline & $3 \mathrm{a}$ & $1.953(0.752-5.072)$ & 0.169 \\
\hline & $3 b$ & $3.299(0.999-10.894)$ & 0.050 \\
\hline & $3 \mathrm{c}$ & $4.471(1.146-17.445)$ & 0.031 \\
\hline \multirow{3}{*}{ Tumour size } & Small & $0(0-0)$ & 0.796 \\
\hline & Medium & 1 & \\
\hline & Large & $0.188(0.001-23.812)$ & 0.499 \\
\hline \multirow{3}{*}{ Lymphatic mets } & No & 1 & \\
\hline & Pelvic & $1.107(0.28-4.373)$ & 0.885 \\
\hline & Pelvic, Extra Pelvic & $8.977(2.732-29.499)$ & 0.000 \\
\hline
\end{tabular}

Table 5: Univariable association with recurrence.

\begin{tabular}{|c|c|c|c|c|}
\hline & & $\mathbf{N}$ & Odds $(95 \%$ CI) & $P$ value \\
\hline \multirow{2}{*}{ Anesthetic technique } & Regional/ Combined & 90 & 1 & 0.273 \\
\hline & GA & 72 & $1.42(0.76-2.65)$ & \\
\hline \multirow{2}{*}{ Age } & $<40$ & 46 & $2.33(1.16-4.67)$ & 0.018 \\
\hline & $40-60$ & 116 & 1 & 0.598 \\
\hline \multirow{2}{*}{ Duration of surgery } & $<3$ hours & 99 & 1 & 0.000 \\
\hline & $>3$ hours & 63 & $3.40(1.76-6.59)$ & \\
\hline \multirow{2}{*}{ Pre OP ca 125} & Not Raised & 59 & 1 & 0.000 \\
\hline & Raised & 103 & $10.03(4.31-23.33)$ & \\
\hline \multirow{7}{*}{ FIGO stage } & $1 \mathrm{a}$ & 53 & 1 & \\
\hline & $1 \mathrm{~b}$ & 18 & $0.88(0.25-3.15)$ & 0.843 \\
\hline & $1 \mathrm{c}$ & 19 & $1.1(0.33-3.64)$ & 0.877 \\
\hline & 2 & 10 & $27.56(3.20-237.80)$ & 0.003 \\
\hline & $3 a$ & 18 & $3.85(1.25-11.80)$ & 0.018 \\
\hline & $3 \mathrm{~b}$ & 17 & $7.39(2.19-24.93)$ & 0.001 \\
\hline & $3 \mathrm{c}$ & 27 & $6.15(2.23-16.99)$ & 0.000 \\
\hline \multirow{2}{*}{ Histological grade } & Grade 1 & 50 & 1 & \\
\hline & Grade 3 & 103 & $8.40(3.73-18.92)$ & 0.000 \\
\hline \multirow{2}{*}{ Tumour size } & Small & 59 & 1 & \\
\hline & Medium & 103 & $8.40(3.73-18.92)$ & 0.000 \\
\hline \multirow{2}{*}{ Lymphatic mets } & No & 105 & 1 & \\
\hline & Pelvic, Extra Pelvic & 57 & $4.94(2.46-9.92)$ & 0.000 \\
\hline
\end{tabular}


Table 6: Multi variable association with recurrence.

\begin{tabular}{|c|c|c|c|c|c|}
\hline & & Beta & SE & Sig. & Odds $(95 \% \mathrm{CI})$ \\
\hline $\begin{array}{l}\text { Anesthetic technique (Regional/ } \\
\text { Combined } ®)\end{array}$ & GA & 41.8 & 215.8 & 0.846 & $0(0-0)$ \\
\hline Duration of surgery $(<3$ hours $\AA)$ & $>3$ hours & 17.1 & 101.2 & 0.866 & $26496407.98(0-0)$ \\
\hline Pre OP ca 125 (Not Raised $\left.{ }^{\circledR}\right)$ & Raised & 11.9 & 828.4 & 0.989 & $0(0-0)$ \\
\hline \multirow{6}{*}{ FIGO stage $(1 \mathrm{a} @)$} & $1 \mathrm{~b}$ & 13.2 & 101.2 & 0.896 & $563662.77(0-0)$ \\
\hline & $1 \mathrm{c}$ & 12.8 & 101.2 & 0.900 & $352575.74(0-0)$ \\
\hline & 2 & 53.4 & 251.0 & 0.832 & $0(0-0)$ \\
\hline & $3 a$ & 13.8 & 101.2 & 0.891 & $1023628.84(0-0)$ \\
\hline & $3 \mathrm{~b}$ & 10.0 & 356.8 & 0.978 & $0(0-0)$ \\
\hline & $3 c$ & -15.9 & 138.5 & 0.908 & $0(0-0)$ \\
\hline Tumour size (Small $®)$ & Medium & 43.3 & 865.6 & 0.960 & $0(0-0)$ \\
\hline Lymphatic mets(No $\left.{ }^{\circledR}\right)$ & $\begin{array}{l}\text { (Pelvic, Extra } \\
\text { Pelvic }\end{array}$ & 3.1 & 5.1 & 0.542 & $22.4(0-492480.23)$ \\
\hline
\end{tabular}

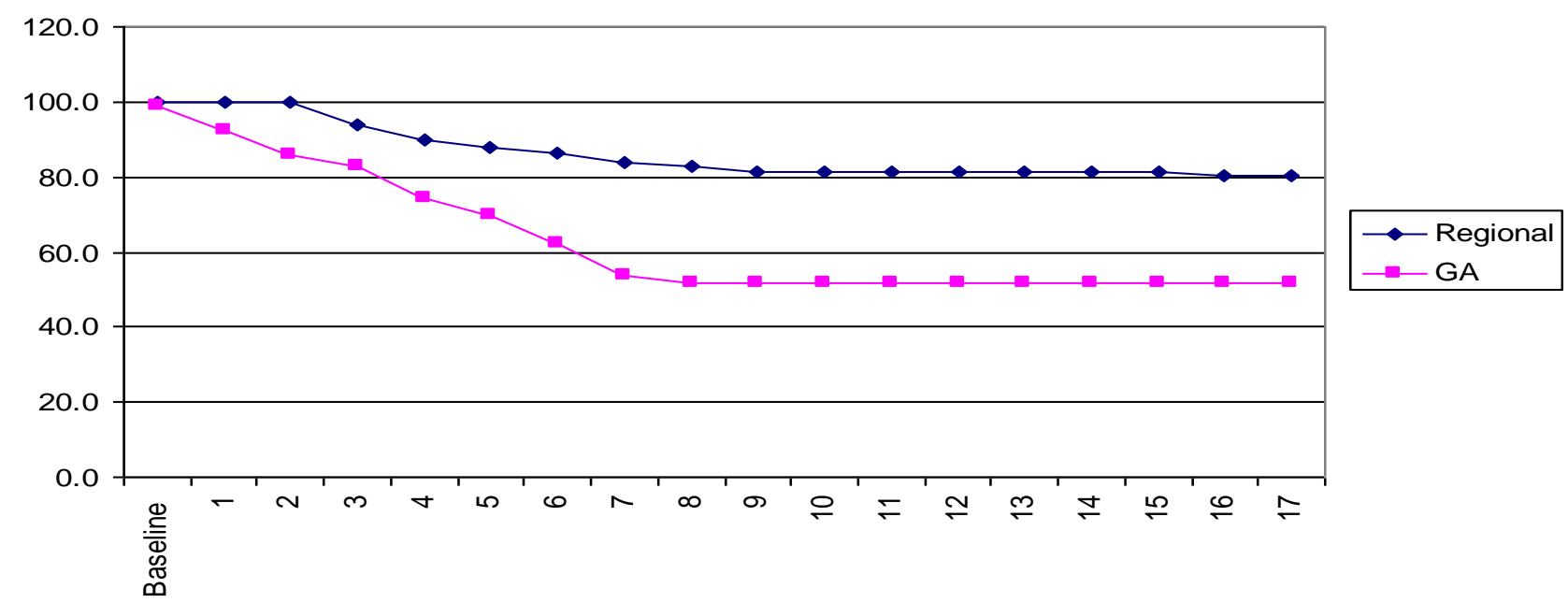

Figure 2: Comparison of survival rate at different time interval.

\section{DISCUSSION}

Increased incidence ovarian serous adenocarcinoma as well as the increased incidence of recurrence and metastasis due to unavoidable residual disease after surgery together with the wide choice of anesthetic techniques and drugs for surgery made us to select this tumour to assess the effect of various factors on recurrence, metastasis and survival.

Recurrence rate, metastasis rate and overall survival rate of 183 patients with ovarian serous adenocarcinoma who underwent surgery under general anesthesia (group G) or regional anesthesia (group R) were evaluated in this study. After adjusting the potential baseline confounders group $\mathrm{G}$ had a significantly higher estimated risk of death in comparison with group $\mathrm{R}$ The overall survival rate at 3 \& 5 years were $82.8 \%$ \& $69.9 \%$ for group $\mathrm{G}$ and 93.87
$87.7 \%$ for group R. After 5 yrs survival rate of $G$ decreased more than that of $\mathrm{G}$.Recurrence free status was $66.7 \%$ in group $\mathrm{R}$ and $51.4 \%$ in group G. No significant difference was found in the recurrence rate between group $\mathrm{R}$ and $\mathrm{G}$. Distant metastasis was found in 18 patients. All those patients underwent surgery under general anaesthesia among the GA drugs used TPS and pancuronium was found to be associated with increased risk of recurrence and metastasis.

The results of our study gives the inference that the disease free survival rate and overall survival rate were better in patients who received regional anesthesia for surgery than those who had general anesthesia.

Literature review shows that the effect of anesthetics on adrenergic system can affect the potential for tumour metastasis and recurrence by suppression of $\mathrm{NK}$ cell activity. ${ }^{3}$ IV anesthetics except propofol and volatile 
anesthetics are known to augment surgically induced immunosuppression. ${ }^{7-10}$ Ketamine by its adrenergic stimulatory properties promote tumourmetastasis.Propofol has no effect on metastasis due to its weak beta adrenergic antagonist properties. The antitumoural protective effect of propofol has been suggested due to its inhibitory effect on cycloxygenase 2 and PGE2 in cancer cells as well as stimulation of immunity response. ${ }^{7-10}$ Opioids by inhibiting cellular and humeral immunity and due to their proangiogenic effect by activation of $\mathrm{Mu}$ opioid receptors found in vascular endothelial cells may promote metastasis. ${ }^{11,12}$ But the pain relief induced by them can attenuate the increased susceptibility for metastasis induced by surgery. Volatile anesthetics up regulate the expression of hypoxic inducible factor $1 \alpha$ (HIF $1 \alpha$ ) which is over expressed in a variety of carcinomas and their metastasis.

Neuraxial anesthesia for cancer surgery can improve long term outcome by attenuating surgical stress response thereby preventing neuroendocrine response which reduces NK cell activity. The balance of Th1/Th2 are better preserved. ${ }^{13,14}$ This attenuates suppression of tumourocidal function of hepatic mononuclear cells. Th1/Th2 imbalance induces CD4 (cluster of differentiation 4)/CD8 imbalance, and serves as a marker of the biological interplay in immune regulation Regional anesthesia decreases the use of systemic opioids. ${ }^{15}$ Even when the opioids are used intrathecally they are used only in small quantities which do not produce immunosuppression. Epidural anesthesia impairs cancer cell proliferation. By inhibiting kinesin motor machinery it produces collapse of micro tubular protrusion which help circulating tumour cells to attach to blood vessels in distant tissues ${ }^{16}$ There is increased activity of voltage gated sodium channels (VGSC)in many malignancies. The level of VGSC $\alpha$ unit correlates highly with metastatic potential of tumours. ${ }^{17-19}$ Cancer cells have high concentration of intracellular sodium and are usually more depolarized .The highly selective VGSC blocker terodotoxin (TTX) inhibits the metastatic behavior in breast, prostate and lung cancer cells. ${ }^{17-21}$ Local anesthetics have a direct role in tumour progression by directly blocking these channels inhibiting VGSC dependent enhancement of cell endocytic membrane activity which affects metastasis. ${ }^{22,23}$

\section{Limitations of the study:}

It is a retrospective analysis. So it identifies only a testable possibility. Prospective randomized control trials are needed to evaluate the outcome with different anesthesia techniques. The sample selection was not randomized. So there can be selection bias. Sample size was different in the two groups. Clinical care was not standardized as the cases were done by different anesthetists and different surgeons. The effects of unmeasured confounding variables could not be excluded. There can be inaccuracies in written records.

\section{CONCLUSION}

Anesthetic management of cancer patients could influence long term outcome decreasing dissemination and metastasis during and after cancer surgery by its effect on surgical stress response. Retrospective studies on the effect of anesthetic techniques and agents show different outcomes either positive or no overall benefit. These studies were done in different tumour types under variable anesthetic regimes. Our study shows marked increase in disease free survival rate and overall survival rate in patients who underwent surgery under regional anesthesia when compared to those who had surgery under general anaesthesia. Immunosuppressive effect of general anesthesia might have contributed to increase in recurrence rate, metastasis rate and mortality in group $G$ patients.

If a positive impact on patient survival can be produced by certain simple changes in the practice of anesthesia this should be recommended as a global protocol. Large scale prospective studies should be conducted for recommending appropriate use of anesthetic techniques and drugs during cancer surgeries for improved survival and quality of life.

\section{ACKNOWLEDGEMENTS}

We thank Dr. Oommen P Mathew, Research Investigator, Population Research Centre, and University of Kerala, India for helping us in the statistical analysis of the data. We also thank Gayathri S Hari, 12 th grade student, Saraswathi Vidyalaya, Vattiyoorkavu, Trivandrum, Kerala who did the literature search and helped us in editing the manuscript. We thank the staff of the Medical Records division, Regional Cancer Centre, Trivandrum, and Kerala for the prompt supply of medical records for analysis.

Funding: No funding sources

Conflict of interest: None declared

Ethical approval: The study was approved by the institutional ethics committee

\section{REFERENCES}

1. Gottschalk A, Brodner G, Van AHK, Elger B, Althaus S, Schulze HJ. Can regional anaesthesia for lymph node dissection improve the prognosis in malignant melanoma? British Journal of Anaesthesia. 2012; 109(2):253-9.

2. Gottschalk A, Sharma S, Ford J, Durieux ME, Tiouririne M. Review article: The role of perioperative period in recurrence after cancer surgery.Anesth Analg. 2010;17(Supp.1):S27-36

3. Melamed R, Rosenne E, Shakhar K, Schwartz Y, Abudarham N, Ben ES. Marginating pulmonary-NK activity and resistance to experimental tumor metastasis: suppression by surgery and the prophylactic use of a beta-adrenergic antagonist and 
a prostaglandin synthesis inhibitor. Brain Behav Immun. 2005;19:114-26.

4. Ben ES. The promotion of tumor metastasis by surgery and stress: immunological basis and implications for psychoneuroimmunology. Brain Behav Immun. 2003;17(Suppl. 1):S27-36.

5. Smyth MJ, Godfrey DI, Trapani JA. A fresh look at tumor immunosurveillance and immunotherapy. Nat Immunol. 2001;2:293-9.

6. Bonnet F, Marret E. Influence of anesthetic and analgesic techniques on outcome after surgery. $\mathrm{Br} \mathrm{J}$ Anaesth. 2005;95:52-8.

7. Melamed R, Bar-Yosef S, Shakhar G, Shakhar K, Ben-Eliyahu S. Suppression of natural killer cell activity and promotion of tumor metastasis by ketamine, thiopental, and halothane, but not by propofol: mediating mechanisms and prophylactic measures. Anesth Analg. 2003;97:1331-9.

8. Markovic SN, Knight PR, Murasko DM. Inhibition of interferon stimulation of natural killer cell activity in mice anesthetized with halothane or isoflurane.Anesthesiology. 1993;78:700-6.

9. Erskine R, Janicki PK, Ellis P, James MF. Neutrophils from patients undergoing hip surgery exhibit enhanced movement under spinal anesthesia compared with general anesthesia. Can J Anaesth. 1992;39:905-10.

10. Loop T, Scheiermann P, Doviakue D, Musshoff F, Humar M, Roesslein M, et al. Sevoflurane inhibits phorbol-myristate-acetate-induced activator protein1 activation in human $\mathrm{T}$ lymphocytes in vitro: potential role of the p38-stress kinase pathway. Anesthesiology. 2004;101:710-21.

11. O'Riain SC, Buggy DJ, Kerin MJ, Watson RW, Moriarty DC. Inhibition of the stress response to breast cancer surgery by regional anesthesia and analgesia does not affect vascular endothelial growth factor and prostaglandin E2. Anesth Analg. 2005;100:244-9.

12. Beilin B, Shavit Y, Trabekin E, Mordashev B, Mayburd E, Zeidel, et al. The effects of postoperative pain management on immune response to surgery. Anesth Analg. 2003;97:822-7.

13. Wada H, Seki S, Takahashi T, Kawarabayashi N, Higuchi $\mathrm{H}$, Habu Y, et al. Combined spinal and general anesthesia attenuates liver metastasis by preserving TH1/TH2 cytokine balance. Anesthesiology 2007;106(3):499-506.
14. Bar YS, Melamed R, Page GG, Shakhar G, Shakhar $\mathrm{K}$, Ben ES. Attenuation of the tumor-promoting effect of surgery by spinal blockade in rats. Anesthesiology. 2001;94:1066-73.

15. Moller JF, Nikolajsen L, Rodt SA, Ronning H, Carisson PS. Thoracic paravertebral block for breast cancer surgery: a randomised double blind study.Anesth Analg. 2007;105:1848-51.

16. Yoon JR, Whipple RA, Bazer EM, Cho EH, Matrone MA, Peckham M, et al. Local anaesthetics inhibit kinesin motility and micro tentacle protrusions in human epithelial and breast tumour cels. Breast Cancer Res Treat. 2011;129:691-701.

17. Brackenbury WJ. Voltage gated sodium channels and metastatic disease. Channels (Aus-tin). 2012;6:5

18. Fraser SP, Diss JK, Chioni AM, Mycielska ME, Pan $\mathrm{H}$, Yamaci RF, et al. Voltage gated sodium channel expression and potentiation of human breast cancer metastasis. Clin Cancer Res. 2005;11:5381-9.

19. House CD, Vaske CJ, Schwartz AM, Obias V, Frank B, Luu $\mathrm{T}$, et al .Voltage gated $\mathrm{Na}+$ channel SCN5A is a key regulator of a gene transcriptional network that controls colon cancer invasion. Cancer Res. 2010;70:6957-67.

20. Roger S, Rollin J, Barascu A, Besson P, Raynal PI,Iochmann S, et al. Voltage gated sodium channels potentiate the invasive capacities of human non small cell lung cancer cell lines.int $\mathrm{J}$ Biochem Cell Bio. 2007;39:774-86.

21. Yidirim S, Altun S, Gumushan H, Pate A and Djamgoz MB. Voltage gated sodium channel activity promotes prostate cancer metastasis in vivo. Cancer Lett. 2012;323:58-61.

22. Roger S, Rollin J, Barascu A, Besson P, Raynal PI, Iochmann $\mathrm{S}$, et al. Voltage gated sodium channels potentiates the invasive capacities of human non small cell lung cancer cell lines. Int J Biochem Cell Biol. 2007;39:774-86.

23. Yidrim S, Altun S, Gumushan H, Patel A, Djamgoz MB. Voltage gated sodium channel activity promotes prostatate cancer metastasis in vivo. Cancer Lett. 2012;323:58-61.

Cite this article as: Sudha P, Koshy RC. Analysis of the effects of drugs and techniques used in anesthesia on tumour recurrence, metastasis and survival in ovarian serous adenocarcinoma. Int Surg J. 2016;3:6270 . 